\title{
Human capital spillovers, productivity and regional convergence in Spain*
}

\author{
Raul Ramos ${ }^{1}$, Jordi Suriñach ${ }^{1}$, Manuel Artís ${ }^{1}$ \\ ${ }^{1}$ Grup d'Anàlisi Quantitativa Regional (AQR-IREA), University of Barcelona, Department of Econometrics, \\ Statistics and Spanish Economy, Avda. Diagonal 690, 08034 Barcelona (Spain). (e-mail: rramos@ub.edu, \\ jsurinach@ub.edu, manuel.artis@ub.edu)
}

\begin{abstract}
This paper analyses the differential impact of human capital, in terms of different levels of schooling, on regional productivity and convergence. The potential existence of geographical spillovers of human capital is also considered by applying spatial panel data techniques. The empirical analysis of Spanish provinces between 1980 and 2007 confirms the positive impact of human capital on regional productivity and convergence, but reveals no evidence of any positive geographical spillovers of human capital. In fact, in some specifications the spatial lag presented by tertiary studies has a negative effect on the variables under consideration.
\end{abstract}

JEL Classification: O18, O47, R23

Keywords: Regional convergence, productivity, human capital composition, geographical spillovers.

\footnotetext{
* The research leading to these results has received funding from the European Community's Seventh Framework Programme (FP7/2007-2013) under grant agreement $n^{\circ}$ 216813. Jordi Suriñach and Manuel Artís wish to express their gratitude for the support received from the Spanish Ministry of Education and Science through the project ECO2009-12678. We would like Enrique López-Bazo, participants at the $3^{\text {rd }}$ World Congress of the Spatial Econometrics Association and to three anonymous referees for his comments on a previous version of this paper. The usual disclaimer applies.
} 


\section{Introduction and objectives}

Assessing regional convergence is an important issue both at the supranational (see, for example, Arbia et al. 2009 for an analysis of the EU regions) and national levels. Spain provides a good example at the level of an individual country. The meta-analysis by LópezBazo et al. (2001) included 19 different studies and the number of published reports examining regional convergence in Spain has grown since then. The presence of significant gaps between Spain's northern and southern regions and the process of political decentralization in the country over the last few decades have attracted the interest of scholars interested in analysing the evolution and sources of this regional convergence (de la Fuente, 2002).

In this paper, we analyse the impact of human capital accumulation to explain regional differences in productivity and regional convergence in Spain. In fact, the role of human capital on economic growth has been highlighted by different authors. Mankiw et al (1992) augmented the Solow model with human capital as an additional production factor while endogenous growth models (Lucas, 1988; Romer, 1989) directly relate human capital and technology adoption. The main conclusion of this strand of the literature is that countries and regions with higher levels of human capital are supposed to expect higher growth rates than territories with lower levels. However, despite the theoretical predictions of these models, empirical evidence has not been conclusive with studies finding non-significant or even negative effects of human capital on growth (de la Fuente, 2006).

Different explanations have been provided by the literature, but the main criticism is that most works basically rely on human capital stock, which is usually proxied by the average number schooling of years or the percentage of population with secondary or tertiary studies ${ }^{1}$. Some recent papers have also suggested that different schooling levels can have different effects on growth. In particular, Petrakis and Stamatakis (2002) show that primary and secondary education matter more for growth in less developed countries as opposed to more developed economies, where higher education becomes more important. Similar results are found by Vandenbussche et al (2006) and by Pereira and St. Aubyn (2009). The only study to our knowledge that has considered this issue at the regional level is Di Liberto (2008). Focusing on Italian regions, she finds that primary education seems to be important in

\footnotetext{
${ }^{1}$ The quality of data has also been questioned (de la Fuente and Doménech, 2006).
} 
the South while a negative impact of tertiary studies is found for Northern regions. These results suggest that Italy has not been able to capture the positive returns from higher levels of education since economic growth has been associated to low-tech activities where a highly skilled labour force did not play a significant role. But, the role of human capital is not only confined to one particular territory: human capital in one region can also influence the neighbouring ones. Different studies in the field of Urban (Rauch, 1993 or Rosenthal and Strange, 2008) and Regional (Fingleton and López-Bazo, 2006 or López-Bazo et al 2004) Economics have confirmed the existence of positive human capital externalities, but other studies such as Adamson et al (2004), Olejnik (2008) or Fischer et al. (2009) have found the opposite result ${ }^{2}$. For example, Olejnik (2008) has found that the level of human capital in neighbouring locations has a negative influence on the level of per-capita income in a given region. According to this author, one possible explanation for this is that an increase in the level of human resources in one region is caused mainly by migration of the educated population between neighbouring regions, which will have a negative effect for them.

Taking this previous research as a starting point, and as we have previously mentioned, the objective of the paper is twofold: first, to test the influence of different schooling levels on productivity and regional convergence and, second, to analyse if there are differences in the effect of human capital on neighbouring regions depending on its composition. Our study, unlike de la Fuente (2002) and Freire-Serén (2002), focuses on the Spanish NUTS III provinces for the period 1980-2007. As Hierro and Maza (2010) indicated “a regional analysis would involve serious problems of aggregation because the Spanish Autonomous Communities are of widely differing sizes and encompass different number of provinces”. The role played by human capital in promoting Spanish economic growth has been analysed in different studies, although the evidence is mixed. For example, while Gorostiaga (1999) found that the estimated coefficient of human capital is negative and significant, Serrano (1999) and Galindo-Martín and Alvárez-Herranz (2004) found that human capital enters positively into the production function. An additional contribution of the paper is related to the application of recently developed spatial econometric panel data techniques. The main advantage of using panel data in relation to the use of cross-sectional data is that it permits to control for unobservable heterogeneity by the inclusion of region and time fixed effects. Moreover, although space (the geographical location of a unit of analysis

\footnotetext{
${ }^{2}$ As noted by a referee, the lack of consensus about the presence of human capital externalities could be related to differences in the sample period, different proxies of human capital or differences in the geographical scales under consideration.
} 
relative to the others) has always played an important role in this kind of studies, the existence of regional linkages have not been taken into account until some recent studies (Fingleton, 2003, Abreu et al., 2005 or Rey and Janikas, 2005). If spatial dependence is present (as it is expected to be on regional data), it should be removed from data because the violation of independence assumption may lead to misleading conclusions. The use of spatial econometrics techniques will permit to overcome this problem.

The rest of the paper is structured as follows. First, the methodology used in the study is described. Next, in the third section, details on data sources and variable definitions are provided while the empirical results are shown in the fourth section. Last, the paper concludes summarising the main findings.

\section{Methodology}

In order to analyse the contribution of human capital to the growth of regional productivity, we rely on the model by de la Fuente and Domenech (2002) and that has been extensively used in the literature on regional growth and human capital (de la Fuente et al, 2003 for Spain, Ciccone, 2004 for Italy and Committee of the Regions, 2005 for France and Germany). The model is built around a regional production function and a technical progress relation that allows for the diffusion of technical know-how across regions. In particular, we assume that the educational attainment of the population is one of the inputs in a constant-returns CobbDouglas aggregate production function. Taking into account the availability of statistical sources that will permit the use of panel data, the log specification of the production function is the following one:

$$
y_{i t}=\beta_{k} k_{i t}+\beta_{b} h_{i t}+\alpha_{t}+\mu_{i}+\varepsilon_{i t}
$$

where $y_{i t}$ is the log of output per employed worker in province $i$ at time $t, k_{i t}$ is the log of the stock of physical capital per employed worker and $h_{i t}$ is the log of the average number of schooling years. $\alpha_{t}$ are time specific effects that control for all common shocks to the considered regions ${ }^{3}$ while $\mu_{i}$ are region specific effects ${ }^{4}$ that control for all unobservable

\footnotetext{
${ }^{3}$ We have chosen to control for time period fixed effects although we are conscious that, as highlighted by Elhorst (2009), applied researchers often find weak evidence in favour of spatial effects when time-period fixed effects are also accounted for. The explanation is that most variables tend to increase and decrease together in the different regions along time (i. e., in the presence of a common business cycle).
} 
region-specific time invariant effects. The regional fixed effects may capture permanent differences in relative total factor productivity that will presumably reflect differences in R\&D investment and other omitted variables. Last, $\varepsilon_{i t}$ is an independently and identically distributed error term for $i$ and $t$ with zero mean and variance $\sigma^{2} . \beta_{k}$ and $\beta_{h}$ are the parameters that summarise the factor contribution to regional productivity.

Taking into account that our objective is to analyse the impact of the different schooling levels, we decompose the level of human capital into three components that indicate the relative contribution of primary $\left(p_{i t}\right)$, secondary $\left(s_{i t}\right)$ and tertiary $\left(t_{i t}\right)$ studies to the $\log$ of the average number of schooling years in a particular province at time $t .^{5}$ Equation (1) is then modified to take into account the potentially different effect of each of these components:

$$
y_{i t}=\beta_{k} k_{i t}+\beta_{p} p_{i t}+\beta_{s} s_{i t}+\beta_{t} t_{i t}+\alpha_{t}+\mu_{i}+\varepsilon_{i t}
$$

As highlighted by Fingleton and López-Bazo (2006), most empirical analysis taking as the starting point the estimation of production functions at the regional level, is that regions have been considered isolated economies. However, theoretical and empirical arguments suggest that regions, as well as not being homogeneous, are also not independent. If the influence of spatial location on the process of growth is ignored, results could be biased and hence conclusions could be misleading. For this reason, equation (2) is augmented specifying the interaction between the different regions. Recent studies adopting a similar approach, such as Arbia et al (2009) incorporate substantive spatial dependence, meaning that spatial effects propagate to neighbouring regions by means of endogenous as well as exogenous variables. This kind of specification is strictly linked to theoretical growth models which consider spatial externalities in the form of technology transfer or knowledge diffusion due to the accumulation of factors in the surrounding area (see, for example, López-Bazo et al., 2004). Moreover, as we will see below, in this case statistical tests confirm theoretical predictions.

\footnotetext{
${ }^{4}$ The regional specific effects may be treated as fixed effects or as random effects. As usual in the literature, in our empirical analysis the decision of including fixed or random effects will be taken on the basis of the results of the Hausman test. Its joint significance will also be tested using Likelihood Ratio (LR) tests.

${ }^{5}$ The average number of schooling years is as a weighted average of the number of schooling years associated to each level of studies and the proportion of workers in each level. The contribution of each level of studies to the average number of schooling years is the result of multiplying the share of people with that level by the number of years required to obtain that level. For example, if the number of schooling years associated to primary studies is 5, to secondary studies 10 and to tertiary studies 15, and the relative shares of workers are $10 \%, 60 \%$ and $30 \%$, the average number of schooling years is 11 and the contributions of each level are 0.5, 6 and 4.5.
} 
Taking this into account, equation (2) is augmented including spatial lags of the endogenous variable (values of the endogenous variable observed in neighbouring regions):

$$
y_{i t}=\delta \sum_{j=1}^{N} w_{i j} y_{j t}+\beta_{k} k_{i t}+\beta_{p} p_{i t}+\beta_{s} s_{i t}+\beta_{t} t_{i t}+\alpha_{t}+\mu_{i}+\varepsilon_{i t}
$$

where $\delta$ is the spatial autoregressive coefficient and $w_{i j}$ is each of the elements of the spatial weights matrix $W$ that describes the spatial arrangement of the different regions. In our empirical analysis, we will consider geographical distance to define the elements of $W$, more precisely the inverse of great-circle distance ${ }^{6}$ between province capitals ${ }^{7}$, which is exogenous to the analysed relationship ${ }^{8}$. As usual in the literature, and in order to normalize the outside influence upon each region, the weight matrix has been standardized such that the elements of a row sum up to one.

Equation (3) is also enlarged with spatially lagged independents variables that will permit to analyse the existence of geographical spillovers among the considered regions. In particular, the model including physical capital and human capital spillovers will be as follows:

$$
\begin{aligned}
y_{i t}= & \delta \sum_{j=1}^{N} w_{i j} y_{j t}+\beta_{k} k_{i t}+\beta_{p} p_{i t}+\beta_{s} s_{i t}+\beta_{t} t_{i t}+ \\
& +\gamma_{k} \sum_{j=1}^{N} w_{i j} k_{j t}+\gamma_{p} \sum_{j=1}^{N} w_{i j} p_{j t}+\gamma_{s} \sum_{j=1}^{N} w_{i j} s_{j t}+\gamma_{t} \sum_{j=1}^{N} w_{i j} t_{j t}+ \\
& +\alpha_{t}+\mu_{i}+\varepsilon_{i t}
\end{aligned}
$$

Equation (4) can also be transformed to derive convergence equations, where growth in a region over a given period is inversely related to its initial income as a result of the mechanism of convergence towards its steady state caused by decreasing returns to capital accumulation $^{9}$. Regional fixed effects and the additional variables in the specification

\footnotetext{
${ }^{6}$ The great-circle distance is the shortest distance between any two points on the surface of a sphere and it has been computed using STATA's globdist command.

${ }^{7}$ Latitude and longitude data for capital cities of the Spanish provinces have been obtained from the Instituto Geográfico Nacional (http://www.ign.es/ign/es/IGN/BBDD_GRAVIMETRICO.jsp).

${ }^{8}$ The results are robust to different specifications of the matrix such as the inverse of the distance to the square or the binary contiguity matrix for the 47 continental provinces. The detailed results are available from the authors on request.

${ }^{9}$ The derivation of the convergence equation from a production function framework with regional externalities can be found in López-Bazo et al. (2004), pp. 46-50.
} 
(physical capital and human capital) control for factors determining differences in the steady states across regions. In particular, the convergence equation in the context of this model will be as follows:

$$
\begin{aligned}
y_{i t}-y_{i t-1}= & \delta \sum_{j=1}^{N} w_{i j}\left(y_{i t}-y_{i t-1}\right)+\beta_{y} y_{i t-1}+\beta_{k} k_{i t-1}+\beta_{p} p_{i t-1}+\beta_{s} s_{i t-1}+\beta_{t} t_{i t-1}+ \\
& +\gamma_{k} \sum_{j=1}^{N} w_{i j} k_{j t-1}+\gamma_{p} \sum_{j=1}^{N} w_{i j} p_{j t-1}+\gamma_{s} \sum_{j=1}^{N} w_{i j} s_{j t-1}+\gamma_{t} \sum_{j=1}^{N} w_{i j} t_{j t-1}+ \\
& +\alpha_{t}+\mu_{i}+\varepsilon_{i t}
\end{aligned}
$$

As Temple (2001) highlights, this specification is preferred to the analysis of the relation between the change in output and the change in education as in this case causality could run from output (or anticipated output) to education, and not vice versa. As long-run changes in average educational attainment are driven by government policy, it seems plausible that as output and tax revenues increase, governments will often allocate more resources to education, and attainment will rise for a transitional period. This critique does not apply to the specification between output growth and the initial level of human capital as considered here. Moreover, the use of schooling years (instead of enrolment rates) and panel data makes more unlikely that reverse causation could explain a positive and significant effect of human capital and growth (de la Fuente and Domenech, 2006) ${ }^{10}$.

In the fourth section of the paper, we will estimate both the production function in levels and the convergence equation in order to test the direct impact of human capital and through geographical spillovers on regional development. In both cases, we will apply Maximum Likehood (ML) procedures for the estimation of spatial panel data models as implemented in the MATLAB routines by Elhorst $(2009)^{11}$. One advantage of the ML procedures in relation to the Instrumental Variables/Generalized Method of Moments (IV/GMM), as the ones proposed by Kelejian et al (2006), is that instruments usually include spatially lagged independent variables, a requirement that will not permit to test the influence of spatial spillovers.

\footnotetext{
${ }^{10}$ An additional issue related to the estimation of equation is the potential endogeneity of $y_{i t-1}$ in equation (5). However, the literature analysing the role of geographical spillovers has systematically ignored this issue. A remarkable exception is Badinger et al. (2004).

${ }^{11}$ These routines are freely available at http://www.regroningen.nl/elhorst/software.html
} 


\section{Data sources, variable definition and preliminary analysis}

As stated above, we analyse the influence of human capital on Spanish regional productivity and convergence during a period in which there was a marked accumulation of education and physical capital together with its trade opening after the integration into the European Union.

We have used yearly data for Gross Domestic Product (GDP), productive capital stock, employment and human capital indicators for the Spanish 50 provinces (NUTS III regions) for the period 1980-2007. The source for GDP is the Instituto Nacional de Estadística (INE) ${ }^{12}$. INE Regional Accounts statistics provide an homogenous series in real terms for the period 1995-2007 but data for the period 1980-1994 is only provided in nominal terms. For the period 1980-1994, we have used provincial Consumer Price Indexes (CPI) from the same source as deflators. Provincial data on net productive capital stock in real terms are available from "El stock y los servicios del capital en España y su distribución territorial”, by the FBBVA-IVIE ${ }^{13}$ for the period 1964-2007. The methodology applied to obtain the series of net capital stock is built on the perpetual inventory method and based on OECD recommendations. ${ }^{14}$ The source for provincial employment and different human capital indicators is "Capital Humano en España y su distribución provincial” by IVIEBancaja $^{15}$ In particular, the availability of detailed information on the average number of schooling years of the working population ${ }^{16}$ and the relative share of the different schooling levels has made possible to decompose the variable into three components related to primary, secondary and tertiary studies.

Figure 1 shows the evolution between 1980 and 2007 of the standard deviation of the log of regional GDP per worker, the usual tool to check for sigma-convergence. As we can see, regional disparities in labour productivity have substantially decreased in the analysed period: the value of the standard deviation has dropped from values around the 0.26 in 1980 to 0.12 in 2007, although there has been a stop since mid-nineties. A similar conclusion is obtained when annualized growth rates of GDP per worker between 1980 and 2007 are

\footnotetext{
${ }^{12} \mathrm{http} / / \mathrm{www}$.ine.es/jaxi/menu.do?type=pcaxis\&path=\%2Ft35/p010\&file=inebase $\& \mathrm{~L}=0$

13 http://www.fbbva.es/TLFU/microsites/stock08/fbbva stock08 index.html

14 http://www.fbbva.es/TLFU/microsites/stock08/mult/El_stock_de_capital_NM_2005.pdf

15 http://www.ivie.es/banco/caphumser07.php

${ }^{16}$ Two different calculations of the average number of schooling years are provided in the dataset in order to take into account the reforms introduced in 1990 by the Ley Orgánica General del Sistema Educativo. The data used in the paper are based on the schooling levels previous to the reform (Ley General de Educación - 1970) as most workers in our sample were educated under this system.
} 
regressed on the initial levels (figure 2). Figures 3 and 4 show that there has also been a convergence process both in capital stock per worker and human capital indicators during this period, although the reduction of regional differences has been much more intense in terms of schooling indicators ${ }^{17}$.

Figure 1. Sigma-convergence in regional GDP per worker between 1980 and 2007

Figure 2. Beta-convergence in regional GDP per worker between 1980 and 2007

Figure 3. Beta-convergence in regional capital stock per worker between 1980 and 2007

Figure 4. Beta-convergence in the average years of schooling between 1980 and 2007

Table 1 shows the results of estimating beta convergence regressions using panel data for the 1981-2007 period. The first column of the table shows the results for productivity without any control (unconditional convergence) and including regional and time period fixed effects (conditional convergence). The results reinforce the idea of regional convergence with a speed of $3.4 \%$ in the first case and $5.4 \%$ in the second ${ }^{18,19}$. The time necessary for the provinces to fill half of the gap which separates them from a common steady state is 20.5 years and 12.8 when we compare them with their own steady state. While the speed of conditional convergence for the capital stock is around $3.8 \%$, the value for the average number of schooling years is above $8 \%$.

\footnotetext{
${ }^{17}$ It is worth mentioning that during this period the average number of schooling years of employed workers in Spain increased from 6.5 in 1980 to more than 11 by 2007.

${ }^{18}$ The speed of convergence, interpreted as the annual rate of convergence, is measured as $-\ln \left(1+T \cdot \beta_{y}\right) / T$ where $T$ is the number of years of the considered period. The half life, defined as the time necessary for the economies to fill half of the gap from the steady state, is calculated as $-\ln (2) / \ln \left(1+\cdot \beta_{y}\right)$.

${ }^{19}$ As highlighted by Islam (1995), the natural rate of convergence in a panel data setup is generally believed to be substantially higher than the usual $2 \%$. In particular, and according to the meta-analysis by Abreu et al. (2005), panel data usually provide a speed of convergence around 6 percent. One possible explanation is that this approach permits to control for (unobserved) technological differences across countries. Higgings et al. (2006) have also argued that when the focus is on smaller regions, the speed of convergence also increases.
} 
Table 1. Beta convergence estimates from panel data 1981-2007

\begin{tabular}{lcccccc}
\hline & \multicolumn{2}{c}{ GDP per worker } & \multicolumn{2}{c}{ Capital stock } & \multicolumn{2}{c}{ Schooling years } \\
& Unconditional & Conditional $^{\mathrm{a}}$ & Unconditional $^{\text {Conditional }}{ }^{\mathrm{a}}$ & Unconditional $^{\text {Conditional }^{\mathrm{a}}}$ \\
\hline Coefficient & $-0.054^{* * *}$ & $-0.119^{* * *}$ & $-0.055^{* * *}$ & $-0.066^{* * *}$ & $-0.021^{* * *}$ & $-0.291^{* * *}$ \\
Speed of convergence & $3.4 \%$ & $5.4 \%$ & $3.4 \%$ & $3.8 \%$ & $1.7 \%$ & $8.3 \%$ \\
Half-life & 20.5 & 12.8 & 20.5 & 18.0 & 41.4 & 8.4 \\
$\mathrm{R}^{2}$ & 0.088 & 0.194 & 0.139 & 0.381 & 0.031 & 0.188 \\
\hline
\end{tabular}

${ }^{a}$ Regional and time periods fixed effects included, but no additional regressors.

$* * * \mathrm{p}<0.01 ; * * \mathrm{p}<0.05 ; * \mathrm{p}<0.1$

The preliminary analysis of data seems to confirm the results by de la Fuente (2002) on the relevance of physical and human capital accumulation as a source of convergence between Spanish regions in the considered period. In the next section, we estimate the models discussed in section 2 in order to confirm this preliminary evidence.

\section{Results}

In this section, we present the results of estimating the models discussed in section 2 using the data for the 50 Spanish provinces between 1980 and 2007. In particular, the results of estimating the production function in levels are shown in table 2, while the results of estimating convergence equations are shown in table 3.

In this sense, it is worth mentioning that, although our empirical specifications incorporate regional externalities on the basis of theoretical considerations, we apply the usual modelling approach: first, we have started estimating a basic specification, without spatial lags of the endogenous or the exogenous variables and including sequentially time-period and regional fixed effects. Second, a Hausman test to select between fixed and random effects and the joint significance of the effects has been calculated. Next, we have computed the LM and robust LM statistics (proposed by Anselin et al (2006) and adapted by Elhorst (2009) to the context of panel data) in order to test for the null hypothesis of no spatial lag of the endogenous variable and no spatial error in the models. In the case that both groups of tests lead to the non rejection of the null hypothesis, this will imply that there are no geographical spillovers in the production function and the convergence equation. However, in case the null 
hypothesis of no spatial lag or no spatial error are rejected, then it will be necessary to include a spatial lag of regional productivity or to consider a spatial error model, respectively.

Table 2. Production function estimates

\begin{tabular}{|c|c|c|c|}
\hline $\log (\mathrm{GDP} \text { per worker })_{\mathrm{t}}$ & $\begin{array}{c}\text { Model } 1 \\
\text { OLS }\end{array}$ & $\begin{array}{c}\text { Model } 2 \\
\text { ML }\end{array}$ & $\begin{array}{c}\text { Model } 3 \\
\text { ML }\end{array}$ \\
\hline $\log \left(\right.$ physical capital stock per worker) ${ }_{t}$ & $0.738 * * *$ & $0.704 * * *$ & $0.689 * * *$ \\
\hline $\log \left(\right.$ average years of primary studies) ${ }_{t}$ & -0.004 & -0.006 & -0.009 \\
\hline $\log \left(\right.$ average years of secondary studies) ${ }_{t}$ & -0.005 & -0.009 & -0.014 \\
\hline log(average years of tertiary studies) ${ }_{t}$ & $0.025 * *$ & $0.021^{* *}$ & $0.017 * *$ \\
\hline Spatial lag of $\log (\text { GDP per worker })_{\mathrm{t}}$ & & $0.397 * * *$ & $0.161^{* *}$ \\
\hline Spatial lag of log(physical capital stock)t & & & $0.465^{* * *}$ \\
\hline Spatial lag of $\log$ (primary studies) ${ }_{t}$ & & & -0.036 \\
\hline Spatial lag of $\log$ (secondary studies) & & & 0.091 \\
\hline Spatial lag of $\log$ (tertiary studies) $)_{\mathrm{t}}$ & & & $-0.076^{* *}$ \\
\hline Time fixed effects & Yes & Yes & Yes \\
\hline Regional fixed effects & Yes & Yes & Yes \\
\hline R-squared & 0.892 & 0.953 & 0.954 \\
\hline Corr-squared & & 0.894 & 0.895 \\
\hline Observations (50 provinces x 27 years) & 1350 & 1350 & 1350 \\
\hline LR-test joint significance regional fixed effects & $2180.240 * * *$ & $2141.987 * * *$ & $2108.056^{* * *}$ \\
\hline Hausman test-statistic (fixed vs random) & $266.430 * * *$ & $106.820 * * *$ & $60.111^{* * *}$ \\
\hline LM test no spatial lag & $23.771 * * *$ & & \\
\hline Robust LM test no spatial lag & $40.712^{* * *}$ & & \\
\hline LM test no spatial error & $1.703^{*}$ & & \\
\hline Robust LM test no spatial error & $18.651^{* *}$ & & \\
\hline
\end{tabular}

$$
* * * \mathrm{p}<0.01 ; * * \mathrm{p}<0.05 ; * \mathrm{p}<0.1
$$

Column 1 of table 2 shows the results of estimating the basic specification of the production function including regional and time-period fixed effects. According to these estimates, we find that both physical capital stock and the average number of schooling years for tertiary studies enter the equation with positive and significant coefficients. The magnitude of the coefficient for physical capital is around 0.7 which is clearly higher than estimates in previous studies (i.e., de la Fuente et al. 2003 estimated the effect of physical capital around 0.3). A Hausman test for choosing between the random and the fixed effect specification clearly discriminates in favour of the latter and the LR tests clearly rejects the hypothesis of the no joint significance of the regional fixed effects. If we look at the results of the LM and robust LM tests, the LM test for no spatial error rejects the null at the $10 \%$ 
significance level while the robust test for no spatial lag rejects it any significance level, while the robust test is also more significant for no spatial lag. Taken into account the results of these tests, as there are problems of spatial dependence, the estimates are inconsistent (Anselin, 1988)

Column 2 of table 2 shows the results obtained when including the spatial lag of the endogenous variable. The results are not substantially different to the previous ones. The spatial lag of the endogenous variable is positive and statistical significant and physical capital stock and tertiary studies indicator enter the equation with positive and significant coefficients. The inclusion of the spatial lags of the explanatory variables (column 3 of table 2) show positive and significant geographical spillovers associated to physical capital, but spillovers to tertiary studies are negative and significant.

Regarding convergence, the column 1 of table 3 shows the results of estimating the basic specification of the convergence equation with regional and time-period fixed effects. As with the production function, a Hausman test has clearly discriminated in favour of regional fixed effects. As we can see from this table, the coefficient associated to the initial level of GDP per worker is negative and statistically significant, a result that reinforces our previous evidence of the existence of a convergence process between Spanish regions in the considered period. The estimated speed of convergence is $7.2 \%$. Physical capital stock and the indicator associated to secondary studies have a positive and statistically significant influence on regional economic growth. However, the number of average years of primary and tertiary studies are not significant at the usual levels. Again, if we look at the results of the LM and robust LM tests, the conclusion is that the spatial lag model should be preferred in statistical terms to the spatial error models and, as a consequence, results are inconsistent.

The inclusion of the spatial lag of the endogenous variable does not substantially affect the results (column 2 of table 3). The coefficient associated to this variable is positive and statistically significant, which implies that economic growth in neighbour provinces exert a positive influence on convergence. However, the speed of convergence is not affected by the inclusion of this variable. Regarding geographical spillovers (column 3 of table 3), physical capital stock exerts a positive and significant effect on growth while a high level of tertiary studies in neighbouring provinces affects negatively the growth rate of the considered province, a similar result to the one obtained in the production function specification. The spatial lag of the endogenous variable is now only significant at the $10 \%$ level. 
Table 3. Convergence equation estimates

\begin{tabular}{|c|c|c|c|}
\hline $\log (\mathrm{GDP} \text { per worker })_{\mathrm{t}}-\log (\mathrm{GDP} \text { per worker })_{\mathrm{t}-1}$ & $\begin{array}{c}\text { Model } 1 \\
\text { OLS }\end{array}$ & $\begin{array}{c}\text { Model } 2 \\
\text { ML }\end{array}$ & $\begin{array}{c}\text { Model } 3 \\
\text { ML }\end{array}$ \\
\hline Log(GDP per worker) $)_{t-1}$ & $-0.213^{* * *}$ & $-0.213 * * *$ & $-0.226 * * *$ \\
\hline Log(physical capital stock per worker) ${ }_{t}$ & $0.096 * * *$ & $0.095 * * *$ & $0.078 * * *$ \\
\hline Log(average years of primary studies) $)_{t}$ & 0.003 & 0.003 & 0.004 \\
\hline Log(average years of secondary studies) $)_{t}$ & $0.019 * *$ & $0.019 * *$ & $0.024 * *$ \\
\hline Log(average years of tertiary studies) $)_{t}$ & 0.011 & 0.011 & 0.006 \\
\hline Spatial lag of $\log (\text { GDP per worker })_{t}-\log (G D P \text { per worker })_{t-1}$ & & $0.137 * * *$ & $0.111^{*}$ \\
\hline Spatial lag physical capital stock ${ }_{t}$ & & & $0.415^{* * *}$ \\
\hline Spatial lag primary studies $_{\mathrm{t}}$ & & & -0.051 \\
\hline Spatial lag secondary studies $_{\mathrm{t}}$ & & & -0.089 \\
\hline Spatial lag tertiary studies $_{\mathrm{t}}$ & & & $-0.087 * *$ \\
\hline Time fixed effects & Yes & Yes & Yes \\
\hline Regional fixed effects & Yes & Yes & Yes \\
\hline Speed of convergence & 0.072 & 0.072 & 0.074 \\
\hline Half life in years & 9.598 & 9.598 & 9.347 \\
\hline R-squared & 0.218 & 0.225 & 0.256 \\
\hline Corr-squared & & 0.218 & 0.232 \\
\hline Observations (50 provinces x 26 years) & 1300 & 1300 & 1300 \\
\hline LR-test joint significance regional fixed effects & $76.48^{* * *}$ & $120.73 * * *$ & $90.64 * * *$ \\
\hline Hausman test-statistic (fixed vs random) & $50.81 * * *$ & $64.88 * * *$ & $72.38 * * *$ \\
\hline LM test no spatial lag & $8.169 * *$ & & \\
\hline Robust LM test no spatial lag & $18.369 * * *$ & & \\
\hline LM test no spatial error & $7.999 * *$ & & \\
\hline Robust LM test no spatial error & $17.652 * *$ & & \\
\hline
\end{tabular}$$
{ }^{* * *} \mathrm{p}<0.01 ; * * \mathrm{p}<0.05 ;{ }^{*} \mathrm{p}<0.1
$$

Summarising, the empirical analysis in this section permits to affirm that the accumulation of physical capital has a positive effect on regional productivity and growth, not only for the considered province but also for the neighbouring ones. Regarding human capital, the results depend on the considered level: tertiary and secondary studies have a significant and positive effect on productivity and growth, respectively. Primary studies does not exert any positive influence on productivity or growth. The results are also robust regarding the negative geographical spillovers from tertiary studies. One possible explanation of the negative effect of tertiary studies on the neighbouring's region growth (in a context of reduced geographical mobility of workers) is that they compete for highly qualified jobs in 
high added value sectors (Olejnik, 2008; Di Liberto, 2008). Fischer et al. (2009) provide a complementary explanation for these negative spillovers: they argue that it is relative regional advantages in human capital that matter most for labour productivity, so ceteris paribus if neighbour regions increase their human capital, the considered region will be in a worst relative position. Last, it is worth mentioning, that this evidence confirms our initial hypothesis of the different effect of the three considered levels. The results are in line with the findings of Di Liberto (2008) for Italy and Pereira and St Aubyn (2009) for Portugal.

\section{Final remarks}

This paper has considered the effects of human capital spillovers in the Spanish regions in the period 1980-2007. In particular, we have first tested the influence of different schooling levels on regional productivity and growth and, second, we have analysed if there are differences in the effect of human capital on neighbouring regions depending on its composition.

With this aim, we have specified a standard production function and convergence equation and we have applied recently developed spatial panel econometric techniques to estimate the considered relationships. We have detected a positive influence of physical capital on regional productivity and growth, not only for the considered region but also for the neighbouring ones. The composition of human capital is also relevant for improving regional productivity and growth. While tertiary studies have a significant and positive effect on productivity and secondary studies on growth, primary studies have no effect on the considered variables. The results have also pointed the existence of negative geographical spillovers from tertiary studies. One possible explanation of this result is that regions compete for highly qualified jobs in high added value sectors (so it is the relative level of human capital what matters) or that neighbouring regions attract qualified workers to exploit agglomeration economies. Further research will be devoted to the analysis of the mechanisms behind these results.

\section{References}

Abreu M, de Groot H, Florax R (2005) A meta-analysis of beta-convergence: The legendary twopercent. Journal of Economic Surveys 19 (3): 389--420.

Adamson D W, Clark D E, Partridge M D (2004) Do Urban Agglomeration Effects and Household Amenities have a Skill Bias?. Journal of Regional Science 44 (2): 201-224 
Anselin L. (1988) Spatial econometrics: Methods and models. Dordrecht: Kluwer Academic Publishers.

Anselin L, Bera A K, Florax R, Yoon M J (1996) Simple diagnostic tests for spatial dependence. Regional Science and Urban Economics 26 (1): 77-104

Anselin L, Le Gallo J, Jayet H (2006) Spatial panel econometrics. In Matyas L, Sevestre P (eds.) The econometrics of panel data fundamentals and recent developments in theory and practice 3rd ed. Kluwer, Dordrecht, pp. 901-969

Arbia G, Battisti M, Di Vaio G (2009) Institutions and geography: Empirical test of spatial growth models for European regions. Economic Modelling forthcoming.

Badinger H, Müller W G; Tondl G (2004), Regional Convergence in the European Union, 1985- 1999: A Spatial Dynamic Panel Analysis. Regional Studies, 38 (3): 241-253

Ciccone A (2004) Human capital as a factor of growth and employment at the regional level: The case of Italy. Report for the European Commission

Committee of the Regions (2005) Human capital as a factor of growth and promotion of employment at the regional level: the case of France and Germany. Committee of the Regions Studies E$2 / 2005$

de la Fuente A (2002) On the sources of convergence: A close look at the Spanish regions. European Economic Review 46 (3): 569-599

de la Fuente A (2006) Education and economic growth: a quick review of the evidence and some policy guidelines. In Globalisation challenges for Europe. Prime Minister of Finland's Office Publications 18/2006, pp. 195-212

de la Fuente A, Doménech, R. (2002) Human capital in growth regressions: how much difference does data quality make? An update and further results. CEPR Discussion Paper 3587.

de la Fuente A, Doménech R (2006) Human capital in growth regressions: How much difference does data quality make?. Journal of the European Economic Association 4: 1-36

de la Fuente A, Doménech F, Jimeno J F (2003) Human capital as a factor of growth and employment at the regional level: The case of Spain. Report for the European Commission

Di Liberto A (2008) Education and Italian regional development. Economics of Education Review 27: 94-107

Elhorst J P (2009) Spatial Panel Data Models. In Fischer M M, Getis A (eds ) Handbook of Applied Spatial Analysis. Springer, Berlin

Fingleton B, López-Bazo E (2006) Empirical growth models with spatial effects. Papers in Regional Science 85 (2): 177-219

Fischer M M, Bartkowska M, Riedl A, Sardadvar A, Kunnert A (2009), The impact of human capital on regional labour productivity in Europe. Letters in Spatial and Resource Sciences forthcoming. 
Freire-Serén M J (2002) On the relationship between human capital accumulation and economic growth. Applied Economics Letters 9: 805-808

Galindo-Martín M A, Álvarez-Herranz A (2004) Human capital and economic growth in Spanish regions. International Advances in Economic Research 10 (4): 257-264

Gorostiaga A (1999) ¿Cómo afectan el capital público y el capital humano al crecimiento?. Investigaciones economicas 23: 95 -114

Hierro M, Maza A (2010) Per capita income convergence and internal migration in Spain: Are foreign-migrants playing an important role? Papers in Regional Science forthcoming

Higgins M J, Levy D, Young A T (2006), Growth and Convergence across the United States: Evidence from County-Level Data. Review of Economics and Statistics 88 (4): 671-681

Islam N (1995) Growth Empirics: A Panel Data Approach. Quarterly Journal of Economics 110: $1127-1170$

Kelejian H H, Prucha I R, Yuzefovich Y (2006) Estimation problems in models with spatial weighting matrices which have blocks of equal elements. Journal of Regional Science 46 (3): 507-551

López-Bazo E, Vayá E, Moreno R (2001) Crecimiento y convergencia regional en España: ¿Qué hemos estado midiendo?. In Cabrer B (ed) Análisis Regional. El proyecto Hispalink, Mundiprensa, pp. 129-139.

López-Bazo E ; Vayá E, Artís M (2004) Regional Externalities and Growth: Evidence from European Regions. Journal of Regional Science 44 (1): $43-73$

Lucas R E (1988) On the mechanics of economic development. Journal of Monetary Economics 22: 342

Mankiw G, Romer D, Weil D (1992) A contribution to the empirics of economic growth. Quarterly Journal of Economics 107: 407-437

Olejnick A (2008) Using the spatial autoregressively distributed lag model in assessing the regional convergence of per-capita income in the EU25. Papers in Regional Science 87 (3): 371-385

Pereira J, St Aubyn M (2009) What level of education matters most for growth? Evidence from Portugal. Economics of Education Review 28 (1): 67-73

Petrakis P E, Stamatakis D (2002) Growth and educational levels: A comparative analysis. Economics of Education Review 21 (5): 513-521

Rauch J E (1993) Productivity Gains from Geographic Concentration of Human Capital: Evidence from the Cities. Journal of Urban Economics 34 (3): 380-400

Romer P (1989) Human capital and growth: Theory and evidence. NBER Working Paper 3173

Rosenthal S S, Strange W C (2008) The Attenuation of Human Capital Externalities. Journal of Urban Economics 64 (2): 373-389

Serrano L (1999) Capital humano, estructura sectorial y crecimiento en las regiones españolas. Investigaciones economicas 23: 225-249 
Temple J (2001) Growth effects of education and social capital in the OECD countries. OECD Economic Studies 33: 57-101

Vandenbussche J, Aghion P, Meghir C (2006). Growth distance to frontier and composition of human capital. Journal of Economic Growth 11 (2): 97-127 